\title{
Construction of Core Competency Model for Creative Professional in Universities
}

\author{
Jiantao $\mathrm{Li}^{1, \mathrm{a}^{*}}$ and Zehou Sun ${ }^{2, \mathrm{~b}}$ \\ ${ }^{1}$ Wuhan University of Technology, Wuhan, P. R. China, 430070 \\ ${ }^{2}$ Wuhan University of Technology, Wuhan, P. R. China, 430070 \\ a281783429@qq.com, bszh-63@163.com
}

\begin{abstract}
Keywords: Core competency; Creative professional; University; Factor analysis; Principal component analysis
\end{abstract}

\begin{abstract}
With the rapid development and the raising position of cultural and creative industries in the world, more creative talents are needed and even they are faced with higher requirements. In order to help talents training and improve the quality of graduates in university, this paper firstly quantitatively studies the core competencies of the creative professional organizations through using behavioral event interview and questionnaire survey method. In additional, based on the above 60 factors which could influence the creative industry competency, 6 dimensions are collected at last by factor analysis and principal component analysis methods. What's more, the author builds an organizational core competences model which consists of the 6 dimensions, that is institutional capability, strategic capability, learning capability, resource integration capability, creative management capability and service consciousness. Finally this model provides theoretical reference for university creative professionals to acquire competitive advantages in modern society and cultivate more excellent talents for creative industry.
\end{abstract}

\section{Introduction}

The core competencies are often used to describe the organization's competitive advantages. In 1990, C. K. Prahalad and Gary Hamel introduced the core competency characteristics into organizations for the first time [1]. Liang Jianchun defined the core competency as the combination of competitive Dominant resources, including organized strategy, knowledge, skills, culture and values etc [2]. Recently, researches are mostly focused on public organizations. Zhang Yijiao analyzed educational administrative organization and put forward the core competency model [3]. Liang Jianchun built a core competency model which consists of 6 dimensions and 12 factors for government traffic organization [4]. Pan Jingjing studies provincial government's core competence characteristics [5]. Moreover, some scholars study the core competency of charity organizations [6]. But few studies focus on the core competence of creative professional origination in Colleges.

Recently, the world culture and economy have experienced a vigorous development. People tend to describe "creativity" as an innovational activity that is carried out based on the culture [7]. Then the cultural creative industry is a profit industry with personalized and creational products [8]. This industry is also a key force to improve the core competitiveness of our country, for it makes the diversified competition [9]. Cultural and creative industries are closely related to people's lives. How to make the culture creative industry to play its real role in the national economy transitions? And how could the industry help push forward the economic construction? All these problems are important tasks. Some think the development of cultural and creative industries should change [10]. Others suggest improving cultural and creative industry with the advantage of industrial cluster [11]. 
Moreover, a few scholars believe that the spillover effects of adjacent domains could make use [12]. Although scholars' views vary from each other, but it's generally accepted that talent is a focus part. However China has faced the shortage of creative talents for a long time because of disconnection between college education and society practice. Universities, as main platform to cultivate creative talents, are eager to realize the present situation of creative talents, enhance the quality of personnel and finally meet the industry demand for talents.

According to the above phenomenon and based on organizational core competency, this paper studies the situation of creative professionals in universities and analyses these important factors for university to better cultivate creative talents. Besides, the author considers current national policy, universities' resources and builds the concept model for creative professional in colleges. Moreover this research eventually gives suggestions for improving the core competitiveness of colleges, enhancing the pertinence and effectiveness of creative talents cultivation and helping the development of cultural and creative industries.

\section{Questionnaire Design and Recovery}

The author first collects creative professional's competency factors by interviewing 30 professors and administration staffs of cultural and creative professional. Then the author picks up totally 60 core competencies from all these factors with the help of specialists. Moreover, the paper gives the definition of the above competencies and designs questionnaire based on literature analysis and expert opinions. The questionnaire uses six point rating method to judge factors' importance. " 1 " grade represents very unimportant; "2" grades represents less important; "3" grades represents unimportant; "4" grades represents important; "5" grades represents more important and "6" grades represents very important. Finally, the questionnaire's retest reliability is 0.923 after the testing and adjustment. In total, the author got 201 recoveries of questionnaires and 169 recycling effective copies. So the recovery rate is $92.63 \%$ and the effective rate is $84.08 \%$.

\section{Descriptive Statistics}

The importance of these factors represents their use for helping acquire competitive advantage. The author classifies the factors which get 1 grade, 2 grades and 3 grades as not important factors and other factors which get 4 grades, 5 grades and 6 grades as important. Then counts the frequency of each factors and calculates the importance proportion, as shown below: 
Table 1 Factors' Importance Proportion

\begin{tabular}{l|c|l|c|l|c}
\hline \multicolumn{1}{c|}{ Factors } & Rate & \multicolumn{1}{c|}{ Factors } & Rate & \multicolumn{1}{c}{ Factors } & Rate (\%) \\
\hline Humanities art & 88.6 & Resource & 84.4 & Market research & 71.2 \\
Creative ability & 87.0 & Industry - Academy - & 80.4 & Social service & 78.4 \\
Resource allocation & 86.9 & Responsibility sense & 79.5 & Media literacy & 79.3 \\
Goal oriented & 86.8 & Commercial & 70.6 & Academic ability & 70.4 \\
Learning ability & 86.8 & Evaluation \& & 70.7 & Academic experts & 70.1 \\
Knowledge level & 86.5 & Democratic & 78.1 & Compressive capacity & 69.8 \\
System innovation & 86.4 & Executive ability & 77.7 & School situation & 69.5 \\
Coordination ability & 85.5 & People oriented & 77.2 & Material resources & 69.3 \\
Resource absorption & 85.3 & Academic & 76.3 & Research ability & 69.1 \\
Human resources & 85.0 & Practical ability & 75.9 & Public relation & 68.8 \\
Leadership & 80.9 & Teaching attitude & 75.7 & Crisis management & 68.6 \\
System administration & 84.2 & Communication skills & 75.4 & Teachers' service life & 68.5 \\
Innovation ability & 83.9 & Professional & 74.5 & Global view & 68.2 \\
Teaching ability & 83.1 & Team innovation & 73.7 & Self-management & 68.1 \\
Harmonious & 82.6 & Achievement & 73.2 & Effective supervision & 67.9 \\
Scientific research & 82.2 & Professional & 67.6 & Marketing ability & 72.9 \\
Foreign exchange & 81.4 & Knowledge system & 72.1 & Native thinking & 67.4 \\
Strategic management & 81.4 & Information & 71.5 & Self-development & 67.4 \\
Seize opportunity & 81.0 & Team building & 71.3 & culture & 67.3 \\
Cooperation & 80.9 & Interdisciplinary & 71.2 & Planning ability & 66.5 \\
\hline
\end{tabular}

From Table 1, the most important factor is the "humanities and arts". And the importance proportions of "culture" and "planning ability" are both less than $67.4 \%$ but more than 50\%, which represents they are though not pivotal features but still affect the competitive power of organization. Therefore, we can take these indicators to evaluate the core competency of creative professionals.

\section{Analysis Results}

Through SPSS22.0 software, results show that the questionnaire's Cronbach a coefficient is 0.931, indicating that the sample data has higher reliability. Moreover, the Bartlett's Test significance is 0.000 , stating that variable data matrix is positive definite. KMO value is 0.866 more than 0.5 which represents there is a strong correlation between these variables, and they are suitable for factor analysis. The related values are as shown in Table 2:

Table 2 KMO and Bartlett's Test

\begin{tabular}{l|c|c}
\hline \multicolumn{2}{c}{ Kaiser-Meyer-Olkin Measure of Sampling Adequacy. } & 0.866 \\
\hline \multirow{3}{*}{ Bartlett's Test of Sphericity } & Approx. Chi-Square & 2520.359 \\
\cline { 2 - 3 } & df & 136 \\
\cline { 2 - 3 } & Sig. & 0.000 \\
\hline
\end{tabular}

The principal component analysis gets six main factors whose characteristic values are all greater than 1.0 after orthogonal rotation. And the six factors explain $68.06 \%$ variance of total variables, so the author take the six main factors as the six dimensions of core competency model. 
Table 3 Characteristic Value and Cumulative Contribution

\begin{tabular}{c|c|c|c|c|c|c|c|c|c}
\hline \multirow{2}{*}{$\begin{array}{c}\text { compo } \\
\text { nents }\end{array}$} & \multicolumn{2}{|c|}{ Original characteristic value } & \multicolumn{3}{c|}{ Load square sum } & \multicolumn{3}{c}{ Load square sum after rotation } \\
\cline { 2 - 10 } & sum & $\begin{array}{c}\text { Variance } \\
(\%)\end{array}$ & $\begin{array}{c}\text { Accumul } \\
\text { ative }(\%)\end{array}$ & sum & $\begin{array}{c}\text { Variance } \\
(\%)\end{array}$ & $\begin{array}{c}\text { Accumulati } \\
\text { ve }(\%)\end{array}$ & sum & $\begin{array}{c}\text { Variance } \\
(\%)\end{array}$ & $\begin{array}{c}\text { Accumulati } \\
\text { ve (\%) }\end{array}$ \\
\hline 1 & 5.314 & 31.257 & 31.257 & 5.314 & 31.257 & 31.257 & 2.903 & 17.075 & 17.075 \\
\hline 2 & 2.149 & 12.644 & 43.901 & 2.149 & 12.644 & 43.901 & 1.997 & 11.750 & 28.824 \\
\hline 3 & 1.147 & 6.747 & 50.647 & 1.147 & 6.747 & 50.647 & 1.901 & 11.181 & 40.006 \\
\hline 4 & 1.091 & 6.415 & 57.062 & 1.091 & 6.415 & 57.062 & 1.810 & 10.646 & 50.652 \\
\hline 5 & 0.977 & 5.748 & 62.811 & 0.977 & 5.748 & 62.811 & 1.552 & 9.131 & 59.783 \\
\hline 6 & 0.892 & 5.248 & 68.059 & 0.892 & 5.248 & 68.059 & 1.407 & 8.276 & 68.059 \\
\hline
\end{tabular}

Based on factor analysis, Table 4 shows six dimensions and their second factors specifically. The six dimensions respectively are "system ability", "strategic ability", "learning ability", "resource integration", "creative management" and "service consciousness".

Table 4 Factor Load and Reliability Coefficient

\begin{tabular}{|c|c|c|c|}
\hline Dimensions & Second factors & Factor load & Alpha coefficient \\
\hline \multirow{2}{*}{ System ability } & System management & 0.912 & \multirow{2}{*}{0.892} \\
\hline & System Innovation & 0.873 & \\
\hline \multirow{3}{*}{ Strategic ability } & Strategic positioning & 0.841 & \multirow{3}{*}{0.915} \\
\hline & Goal oriented & 0.851 & \\
\hline & Resource allocation & 0.877 & \\
\hline \multirow{4}{*}{ Learning capability } & Academic ability & 0.912 & \multirow{4}{*}{0.893} \\
\hline & Team innovation & 0.874 & \\
\hline & Knowledge level & 0.892 & \\
\hline & Culture & 0.845 & \\
\hline \multirow{3}{*}{ Resource integration } & Human resource & 0.882 & \multirow{3}{*}{0.899} \\
\hline & Society resource & 0.901 & \\
\hline & Resource absorption & 0.861 & \\
\hline \multirow{3}{*}{ Creative management } & Creative ability & 0.890 & \multirow{3}{*}{0.887} \\
\hline & Practical ability & 0.863 & \\
\hline & Marketing ability & 0.905 & \\
\hline \multirow{2}{*}{ Service consciousness } & Teaching attitude & 0.874 & \multirow{2}{*}{0.893} \\
\hline & Teaching quality & 0.901 & \\
\hline
\end{tabular}

Dimension one is named "system ability" which reflects the planning and management of system within the organization. It includes "system management" and "system innovation". Dimension two is named "strategic capability" which reflects long-term planning and short-term objectives of the organization. It includes "strategic positioning", "goal orientation" and "resource allocation". Dimension three is named "innovation ability", which reflects organization's overall learning ability and learning atmosphere. It consists of "academic ability", "team innovation", "knowledge level" and "organizational culture". Dimension four is named "resources integration" which includes "human resources", "social resources" and "resources absorption \& transformation". Dimension five is named "creative management" including "creative ability", "practice ability" and "marketing ability". It reflects the whole process from original idea to creative products. Dimension six is 
named "service consciousness" including "teaching attitude" and "teaching quality". It reflects the involvement of creative professionals' teachers.

Drawn by the above analysis, there are eventually 6 dimensions and 17 second factors in the core competency model of university creative professionals, as shown in Fig. 1:

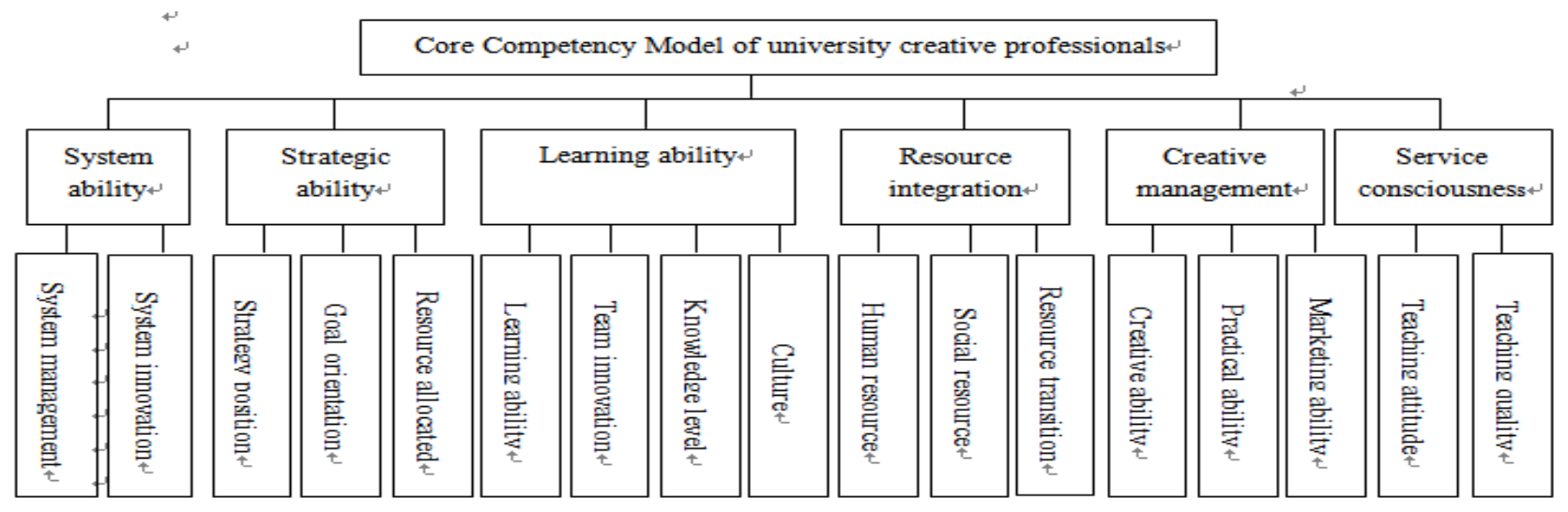

Figure 1. Core competency model of creative professional organization

\section{Summary}

In this paper, the author uses the literature analysis and behavioral event interview method to design questionnaire about core competency of university creative professional organization. From the factor analysis and principal component analysis, six dimensions are collected for constructing the core competency model. As to China, the development of cultural and creative industry has become an important part of national economic transformation. Universities, as the birthplace of high-quality talents, are gradually playing critical role in making up the shortage of talents for cultural and creative industry in our country. According to the core competency model of creative professional organization, it is apparent that university should pay more attention on the following aspects, which are system ability, strategic ability, learning ability, resource integration, creative management and service consciousness. As long as the university strengthens these capabilities, the creative professionals could acquire the competitive position when their graduates compete with other competitors. Meanwhile, the discipline organization can keep the long-term, sustained and healthy development means that they can quickly deliver high-quality talents for cultural and creative industries and keep the rapid development of this industry.

\section{References}

[1] C. K. Prahalad, Gary Hamel, The core competence of the corporation, J. Harvard Business Review. 3(1990) 79-91.

[2] Liang Jianchun, Shi Kan, The general research situation of organizational core competent characteristics, J. Journal of Southwest Nationalities University. 4(2006) 169-171.

[3] Xu Xiaoping, Management, in: Xu Xiaoping (Eds.), Introduction to the organization behavior, science press, Peking, 2014, pp. 25-36.

[4] Liang Jianchun, Fu Xiaoli, Shi Kan, Government transport management organizational core competent feature evaluation, J. Statistics and decision. 19(2007) 79-82.

[5] Pan Jingjing, Liu Lanjing, Chen Xia, Empirical studies on the core competency of the 
provincial government organizations, J. Industrial technology and economy. 3(2008) 120-125.

[6] Huo Xingyan, Lin Yuanhua. Study on the performance model construction of youth sports club, J. Journal of Hebei Institute of Physical Education. 5(2011) 1-3.

[7] Xiang Yong, Research on creative managers' competency of cultural industry, J. Journal of Tongji University. 5(2009) 57-62.

[8] Deng Xiaohui: Research on cultural and creative industries in the new era of technology economy (2006)

[9] $\mathrm{Hu}$ Xiaopeng, Technological innovation and cultural creativity: reflections on the economic rise of developing countries, J. Science Research. 1(2006) 125-129.

[10]Zhu Qixian, Thinking on the development of creative culture industry in northern gulf economic zone, J. Reform And Strategy. 7(2011) 115-117.

[11] Gu Shengzu, Wang Min, Development of cultural and creative industries to promote china's economic transformation, J. Technology Progress And Countermeasures. 6(2010) 44-49.

[12] Hu Bing, The influencing factors of provincial cultural creative industry development in china space measurement, J. Economic geography. 2(2014) 101-107. 